\title{
El concepto de trabajo y la teoría social crítica ${ }^{1}$
}

\author{
José Antonio N oguera
}

Universitat Autònoma de Barcelona

jose.noguera@uab.es

\section{Resumen}

Los actuales debates en torno al concepto de trabajo no siempre han planteado con claridad algunos de los rasgos central es que dicho concepto adopta en la tradición de teoría social crítica que se inicia con M arx. Esta tradición ha puesto a menudo el acento en las relaciones entre el trabajo y la emancipación humana. En esta dirección, el artículo propone tres ejes conceptuales adicionales al ya tradicional de «valorización vs. desprecio» del trabajo: concepto amplio frente a concepto reducido, productivismo frente a antiproductivismo, y centralidad normativa frente a no centralidad del trabajo. D esde estas coordenadas de análisis, se critican algunos tópicos sobre el concepto de trabajo de $M$ arx, y se enumeran diversos caminos por los que las tradiciones marxistas posteriores han desarrollado el mismo. En concreto, se lleva a cabo un análisis y crítica del concepto de trabajo en $\mathrm{H}$ abermas.

Palabras clave: trabajo, teoría social, marxismo, teoría crítica, M arx, $\mathrm{H}$ abermas.

\begin{abstract}
Present discussions on the concept of work have not al ways established clearly some of the central tenets that this concept has acquired in the tradition of critical social theory which begins with $M$ arx. This tradition has often emphasized the relationship between work and human emancipation. In this direction, the article adds three conceptual dichotomies to the more traditional one of "valuation vs. disdain" of work: wide vs. reduced concept of work, productivism vs. antiproductivism, and normative centrality vs. non-centrality of work. From this standpoint, the article criticizes some commonplaces about $M$ arx's concept of work, and list some ways in which later $M$ arxist traditions have develop this concept. Specifically, $\mathrm{H}$ abermas' concept of work is analyzed and criticized in the last part of the article.
\end{abstract}

Key words: work, social theory, marxism, critical theory, $\mathrm{M}$ arx, $\mathrm{H}$ abermas.

1. El presente artículo está parcialmente basado en la tesis doctoral La transformación del concepto de trabajo en la teoría social: La aportación de las tradiciones marxistas (N oguera, 1998), dirigida por Rainer Zoll, y que presenté en septiembre de 1998 en la U niversidad Autónoma de Barcelona. Agradezco a la Generalitat de $C$ atalunya la concesión de una beca de formación de investigadores (FPI), sin la cual la realización de la misma no habría sido posible. 


\section{Sumario}

Introducción: el concepto de trabajo en discusión

Cuatro ejes teóricos para el estudio del concepto de trabajo

El concepto de trabajo en M arx: crítica de al gunos tópicos

El concepto de trabajo en las tradiciones marxistas posteriores
La crítica de $H$ abermas a M arx y al concepto amplio de trabajo

Algunas posibles implicaciones: ¿tiene sentido aún el concepto de trabajo?

Bibliografía

\section{Introducción: el concepto de trabajo en discusión}

Como es bien sabido, en la actualidad se desarrolla en los países capitalistas occidentales una compleja discusión, académica y política, sobre los cambios que se están produciendo en la realidad laboral; esta discusión incluye temas sumamente variados, que hacen referencia al sentido del trabajo, la supuesta «crisis de centralidad» del mismo, las formas no mercantiles de trabajo, los cambios en el trabajo asalariado y en la organización social de la producción, las consecuencias de esos cambios en la estructura social, las propuestas políticas de reducción del tiempo laboral o de disociación de trabajo y renta, etc. Existe ya un volumen de literatura ingente sobre el particular, y de la misma se suele desprender un cierto consenso, a veces algo difuso, en torno a la necesidad de repensar y ampliar el concepto mismo de trabajo «tal y como lo hemos conocido».2

El objetivo de este artículo no es entrar a analizar tales discusiones, sino abordar los prolegómenos de una tarea que a mi juicio resulta previa: la de entender las implicaciones teóricas del concepto de trabajo que subyace a las mismas, y hacerlo desde la tradición de teoría social crítica que se inició con la obra de $\mathrm{M}$ arx. Este análisis es lógicamente previo a estudios concretos o investigaciones empíricas sobre las cuestiones citadas, y puede servir para iluminar al gunos de los supuestos teóricos incuestionados que subyacen en muchos de los actuales debates, así como para reinterpretar los fenómenos empíricos en los que éstos se inspiran. En este sentido, las líneas que siguen tratan de constituir una primera aproximación a este análisis conceptual. ${ }^{3}$

Pero, ¿por qué abordar esa tarea desde la teoría social de orientación marxista 0 «marxiana»? H ay dos razones para ello: en primer lugar, porque se trata de la tradición teórica que más decididamente se inspira en valores emanci-

2. Una panorámica general y reciente de estos debates puede encontrarse en libros como los de Alonso (1999 y 2000), Bauman (1998) o Sennett (1998).

3. A este respecto, he tratado de desarrollar un análisis complementario sobre el problema teórico de la definición del trabajo en N O GUERA (2000), y, de forma menos exhaustiva, sobre la cuestión de la centralidad del trabajo, en N O GUERA (1997). 
patorios al servicio de una transformación social que aumente los grados de autonomía y autorrealización de los individuos; más concretamente, se trata de la tradición que más ha renunciado a cualquier tipo de esencialismo ahistórico que decida de antemano sobre «la naturaleza» de un fenómeno como el trabajo humano (y ello tiene implicaciones que se tratarán más abajo).

Pero también, en segundo lugar, porque la tradición marxista es una de las menos estudiadas por lo que se refiere al tema que nos interesa: los estudios teóricos e históricos sobre el concepto de trabajo casi nunca la tratan de forma sistemática. ${ }^{4}$ Y no se trata únicamente de que esta tradición haya sido poco estudiada por lo que se refiere al concepto de trabajo (algo, por cierto, bastante paradójico para una corriente intelectual que se basa en gran parte en ese concepto); hay que decir también que se trata de la peor estudiada: los prejuicios, tópicos, lugares comunes y lecturas de segunda mano - sobre todo en M arx- se han extendido sobremanera en la literatura sobre el concepto de trabajo.

Q uizá sea necesario aclarar que cuando se habla de «marxistas», normalmente se incluyen dentro del término escuelas, corrientes de pensamiento y autores muy diversos entre sí e incluso opuestos en muchos sentidos. D esde luego, es de rigor el diferenciar entre $M$ arx y los marxistas posteriores que decían inspirarse en él, pero también el distinguir entre diversas clases de marxismo. En este sentido, las aportaciones más interesantes para el análisis del concepto de trabajo provienen sin duda de lo que Perry Anderson $(1973,1976) 0$ M artin Jay (1984) han denominado «marxismo occidental», como tradición contrapuesta a las versiones más «ortodoxas» y doctrinarias del marxismo. Son los «marxistas occidentales» quienes han desarrollado visiones y elaboraciones críticas y originales respecto de la obra de $M$ arx, sin haberla fosilizado como un conjunto de «recetas» intelectuales «listas para el uso».

En definitiva, lo que las tradiciones marxistas y críticas han puesto sobre la mesa de modo harto fructífero es un aspecto relegado (e incluso a veces ignorado) en al gunos de los debates contemporáneos: la cuestión de las relaciones entre el trabajo y la libertad humana; este problema plantea una serie de preguntas conectadas entre sí: jpuede el trabajo ser una actividad generadora de sentido?; ¿va la lógica del trabajo más allá de la racionalidad instrumental o se agota en ella?; ihasta dónde puede retroceder, ontológicamente hablando, la cosificación en las prácticas de trabajo? Éstas son las cuestiones cruciales que estructuran el debate de fondo entre dos importantes pensadores que mantienen posiciones opuestas a este respecto: $\mathrm{M}$ arx y $\mathrm{H}$ abermas. Pero antes de referirnos con más detalle a esta discusión, conviene explicitar las coordenadas de análisis de las que se parte.

4. Por poner sólo dos ejemplos bastante conocidos de entre la literatura sobre el concepto de trabajo, ni el estudio clásico de A. TILGHer (1929) ni el más moderno de H. Applebaum (1992) dedican mucho espacio a las tradiciones marxistas y/o críticas. Una excepción parcial es la obra enciclopédica de Antimo N EGRI (1980-1981). En España, el reciente trabajo histórico de Fernando D íEz (2001) - por lo demás excelente- se limita a los orígenes del concepto moderno de trabajo en el Siglo de las Luces. 


\section{Cuatro ejes teóricos para el estudio del concepto de trabajo}

Con objeto de guiarnos a través de la discusión sobre el concepto de trabajo, podemos definir cuatro ejes teóricos o conceptuales que sirvan para clasificar y estudiar las diversas posturas teóricas al respecto:

\section{a) El eje valorización versus desprecio del trabajo}

Sin duda es éste el eje más tradicional mente estudiado, de tal modo que se ha convertido en la perspectiva dominante en casi todos los estudios históricos sobre el concepto de trabajo. ${ }^{5}$ Este eje, como su propio nombre indica, se refie re a si el trabajo es dignificado y revestido de valor social y cultural positivo 0 si, por el contrario, es despreciado como una actividad innoble; y esas dos posturas, la de valorización y la de desprecio, reflejan las visiones contrapuestas que dominaban, respectivamente, en las sociedades modernas y en las antiguas. El grado extremo de valorización del trabajo podemos definirlo como glorificación del mismo: glorificar el trabajo sería constituirlo en fuente de todo bien y de todo progreso humano; normal mente tal creencia viene acompañada de un canto retórico o poético que elogia las virtudes de todo tipo que acompañan a la actividad laboral en general. Ejemplos de glorificación del trabajo serían los discursos de al gunos predicadores protestantes como Baxter o Wesley, que inspiraron la moderna «ética del trabajo» del capitalismo industrial, 0 las ideas al respecto de Benjamin Franklin, que la aplicaban a la perfección, ${ }^{6}$ o las de filósofos y humanistas renacentistas como Bacon y Buonarotti, moralistas victorianos como Thomas Carlyle, o novelistas como Conrad, Victor H ugo, Zola o Tolstoi.

El eje valorización versus desprecio del trabajo constituye ya, por tanto, un camino muy trillado y tradicional para estudiar el concepto de trabajo. Además, tomar este eje como central en tal estudio conduce con frecuencia a no discriminar suficientemente entre los diferentes tipos de val oración o desprecio del trabajo que se pueden dar, y entre los diferentes motivos y filosofías que los impulsan (así, el liberalismo burgués y el socialismo suelen ser clasificados en una misma categoría de «valorizadores» del trabajo, haciendo abstracción de todas sus diferencias al respecto). Se hace necesario por tanto buscar otros ejes teóricamente más relevantes para los objetivos propuestos. C oncretamente, la adopción de otras tres dicotomías puede resultar fructífera.

5. Por seguir con los ejemplos ya mencionados en la nota 4, tanto el estudio de Adriano TILGHER, H omo faber, como el de H erbert Applebaum, The Concept of Work, se estructuran básicamente en torno a esta dicotomía teórica. O tros ejemplos son los de AN TH ONY (1977), ARENdT (1958), BAT TAGLIA (1951 y 1973), DE GRAZIA (1962), JACCARD (1960), K WANT (1960) N AREDO (1977 y 1997), PIEPER (1952) o TRAN QUILLI (1979).

6. Y que por tal motivo fueron citadas por clásicos como M ARX (1872) o W EBER (1904-05). Véase también, sobre el nacimiento y la consolidación de la «ética del trabajo», el excelente estudio de ROD GERS (1978). 


\section{b) Concepto amplio versus concepto reducido de trabajo}

D enominaremos concepto amplio de trabajo al que considera que una actividad laboral puede tener recompensas intrínsecas a la misma, y que por tanto el trabajo no necesariamente consiste en una actividad pura y exclusivamente instrumental, sino que puede ser - al menos parcialmente- autotélica (tener en ella misma su propio fin)..$^{7}$ Por el contrario, un concepto reducido de trabajo sería aquél que sólo considera posibles recompensas extrínsecas a la actividad en cuestión (recompensas que pueden tomar formas muy distintas: dinero, supervivencia, reconocimiento social, salvación religiosa, etc.); según el concepto reducido, el trabajo es una actividad puramente instrumental, que no puede dar lugar a autorrealización personal al guna, y que supone necesariamente una coerción para la libertad y la autonomía del ser humano.

Las implicaciones de este eje conceptual pueden advertirse mejor si ofrecemos una definición teóricamente más elaborada del mismo a partir del cuadro 1.

Cuadro 1. Conceptos de trabajo en relación con las dimensiones de la acción.

\begin{tabular}{|c|c|c|c|c|}
\hline $\begin{array}{l}\text { Dimensiones } \\
\text { de la acción }\end{array}$ & Criterios de validez & Aplicación al trabajo & $\begin{array}{l}\text { Conceptos } \\
\text { de trabajo }\end{array}$ & \\
\hline $\begin{array}{l}\text { Cognitivo- } \\
\text { instrumental }\end{array}$ & Eficacia y eficiencia & $\begin{array}{l}\text { Producción o creación } \\
\text { de valores de uso }\end{array}$ & & \multirow{4}{*}{ Amplio } \\
\hline \multirow[t]{2}{*}{ Práctico-moral } & \multirow[t]{2}{*}{$\begin{array}{l}\text { Adecuación } \\
\text { normativa }\end{array}$} & $\begin{array}{l}\text { Trabajo como deber } \\
\text { social o disciplina } \\
\text { coercitiva }\end{array}$ & Reducido & \\
\hline & & $\begin{array}{l}\text { Trabajo como medio } \\
\text { de solidaridad social }\end{array}$ & & \\
\hline $\begin{array}{l}\text { Estético- } \\
\text { expresiva }\end{array}$ & Autenticidad & $\begin{array}{l}\text { Autoexpresión y/0 } \\
\text { autorrealización } \\
\text { en el trabajo }\end{array}$ & & \\
\hline
\end{tabular}

En este cuadro observamos tres dimensiones posibles de la acción - inspiradas en la obra de J ürgen $\mathrm{H}$ abermas (1981) - , con sus respectivos criterios de validez, y la posible aplicación que podrían tener a la acción humana específica que es el trabajo:

a) La dimensión cognitivo-instrumental consistiría en la búsqueda de resultados según criterios de eficacia o eficiencia; aplicada al trabajo, correspondería a la producción o creación de val ores de uso.

7. El concepto de actividad autotélica procede de Aristóteles (está conceptualmente implicado en su distinción entre praxis y poiesis), y ha sido recuperado y aplicado al trabajo por autores contemporáneos como ELST ER (1989) o C SIKZENT M IH ALYI $(1975,1990)$. 
b) La dimensión práctico-moral corresponde a los aspectos significativosy al sentido social y moral que tiene toda acción, y se regiría por criterios de corrección o adecuación moral y social; aplicada al trabajo, puede manifestarse, a grandes rasgos, de dos maneras: concibiendo el trabajo como deber social 0 disciplina coercitiva (como la «ética del trabajo» tradicional), o bien entendiéndolo como medio de solidaridad social y de creación de vínculos sociales; puede observarse que, en el primer caso, tenemos una concepción del trabajo que tiende más hacia la racionalidad cognitivo-instrumental, ${ }^{8}$ mientras que en el segundo se abriría el campo para un tipo de racionalidad autónoma respecto de la instrumental, y orientada en un sentido más comunicativo en términos habermasianos.

c) Por último, la dimensión estético-expresiva abarcaría los aspectos de autoexpresión y autorrealización que puede contener la acción humana, y que estarían regidos por criterios de autenticidad; aplicándolos al trabajo, éste sería entendido como un medio de autorrealización personal.

Pues bien, una definición teóricamente más elaborada del concepto amplio de trabajo sería la siguiente: el concepto amplio es el que abarca las dimensiones de la acción que van más allá de la racionalidad instrumental, esto es, el que puede considerar el trabajo no sólo como producción instrumental de valores de uso, sino también, al mismo tiempo, como medio de solidaridad social y de autorrealización personal; el concepto amplio tiende a incorporar así las tres dimensiones o racionalidades que pueden estar presentes en la acción humana: cognitivo-instrumental, práctico-moral y estético-expresiva. El concepto reducido, por el contrario, sólo podría considerar el trabajo bien como acción instrumental destinada a la producción de valor de uso, bien como deber social o disciplina coercitiva; en ambos casos, el concepto reducido supone que el trabajo no puede dar lugar a ningún potencial de autonomía ni de autorrealización individual.

\section{c) Productivismo versus antiproductivismo en relación con el trabajo}

0 tro eje que puede considerarse relevante para estudiar el concepto de trabajo en la teoría social es el que opone una posición productivista a una antiproductivista. No cabe duda de que la palabra productivismo puede tener sentidos muy diversos, y se hace necesario por tanto detallar a cuáles de ellos nos referimos. Concretamente, cabe considerar que una concepción del trabajo es productivista cuando se basa en al guno de los siguientes supuestos teóriCOS:

8. H aberm AS (1981, I: 292 s.) o Zo LL (1991) han mostrado cómo la «ética del trabajo» que provino del protestantismo era en el fondo una manifestación harto acabada de racionalidad instrumental. 
a) Asume la producción de bienes económicos como una finalidad en sí misma o prioritaria sobre cualquier otra (esto es, persigue «la producción por la producción».

b) Equipara toda actividad humana con la producción económica o conside ra que ésta es el «modelo» 0 «paradigma» para entender aquélla.

c) O bien considera las actividades mercantiles como único modelo posible y/o deseable de producción de bienes y servicios.

Un concepto de trabajo se inscribe, por tanto, en una óptica productivista cuando se considera el trabajo y la producción, en sí mismos, como fines compulsivos de la existencia humana, o cuando se toma un modelo «laboral» de acción como punto arquimédico de la existencia humana, o cuando se reduce el trabajo únicamente a la realización de actividades económicas valorables en términos mercantiles; y sería antiproductivista cuando no realiza tales suposiciones. N ótese, a este respecto, que no cabe confundir «producción» y «productivismo»: la producción material siempre será necesaria y básica para cualquier sociedad; el productivismo, la producción por la producción sin importar los objetivos, la glorificación de la producción como tal, es un fenómeno cultural y social específico de una determinada etapa histórica. ${ }^{9}$

\section{d) Centralidad versus no centralidad del trabajo}

Por último, otro eje relevante es el que opone la «centralidad» a la «no centra lidad» del trabajo. ¿Q ué se quiere decir con la expresión centralidad? N o se habla aquí de centralidad del trabajo en el sentido obvio o trivial de que el trabajo es necesario para la supervivencia, sino en el sentido, menos evidente, de centralidad social y cultural: ésta tiene que ver con hasta qué punto constituye el trabajo una instancia básica que estructura las instituciones sociales y la vida de los individuos. $\mathrm{H}$ ay que distinguir claramente, entonces, entre la necesidad material del trabajo y su centralidad social y cultural. El trabajo siempre será «central» en cuanto necesidad material para la subsistencia del género humano; en este sentido, hablar de «centralidad» del trabajo no es más que una perogrullada. Y a este respecto cabe recordar el famoso pasaje de $M$ arx en una de sus cartas a Kugelmann: «C ualquier niño sabe que toda nación se derrumbaría si cesara el trabajo, no digo durante un año, sino aunque no fuese más que durante al gunas semanas» ( $M$ arx, 1868: 180). Ahora bien, también es cierto que el trabajo puede ocupar, social y culturalmente, un lugar más o menos «central» en la vida de los individuos y de la sociedad a la que pertenecen; sólo en la época moderna ha llegado el trabajo a ocupar tanto tiempo y a tener tanta

9. Tampoco cabe confundir producción y trabajo, pero no hay espacio aquí para analizar a fondo esta distinción. V éase, al respecto, N O GUERA (2000). 
importancia en las vidas de los seres humanos, ${ }^{10}$ y no es descabellado esperar que tal situación no sea eterna.

En segundo lugar, conviene distinguir también entre centralidad descriptiva y centralidad normativa del trabajo. La centralidad descriptiva se refiere a la constatación, como una cuestión de hecho, de que el trabajo tiene ese puesto central en la existencia (se trataría, en el fondo, de una versión más de la discusión sobre el teorema de la base y la superestructura, o del debate entre idealismo y materialismo, pero hoy aplicado a la vigencia o la crisis de la usocie dad del trabajo»). La centralidad normativa, por su parte, se refiere a la cuestión política y ética de si el trabajo debe tener esa importancia sociocultural, y de si debe existir un vínculo claro entre trabajo y beneficios sociales diversos (ingresos, supervivencia, ciudadanía, estatus, etc.). Ésta última - la centralidad normativa - es la que parece más relevante para los objetivos propuestos, dado que sus consecuencias teóricas y políticas sobre el concepto de trabajo son mayores que la de una simple constatación empírica y/o descriptiva sobre la centralidad del mismo (por ejemplo, quienes suscriben esta centralidad normativa rechazarán la posibilidad de una renta básica garantizada o incondicional, independiente del trabajo, y favorecerán al guna versión de la «ética del trabajo» moderna). Así, una concepción de la ciudadanía será «trabajocéntrica» cuando asocie normativamente al trabajo la obtención de beneficios sociales como los ingresos económicos, la subsistencia material, el prestigio social, etc. Por el contrario, se prescinde de la centralidad normativa del trabajo cuando se aboga por una disociación entre trabajo y subsistencia, u otro tipo de beneficios.

Los tres últimos ejes que se han definido pueden aplicarse a los principales autores de diversas tradiciones de teoría social marxista o postmarxista - y, en general, al conjunto del pensamiento social - , que traten con al guna amplitud y relevancia del concepto de trabajo. En el cuadro 2 pueden observarse al gunos resultados parciales de este análisis (incluimos también, a título indicativo y ejemplificador, a algunos autores o corrientes de pensamiento no situados en las tradiciones marxistas o críticas).

Evidentemente, carecemos de espacio aquí para entrar en una fundamentación detallada de la clasificación de cada autor en el cuadro. ${ }^{11}$ Pero lo que sí cabe advertir, de entrada, es que los tres nuevos ejes teóricos que se han definido funcionan de forma independiente conceptual mente hablando, por ejemplo: es posible defender el concepto amplio de trabajo tanto desde ópticas productivistas como antiproductivistas; es posible estar a favor de la centralidad normativa del trabajo tanto asumiendo el concepto amplio como el reducido; es posible partir de un punto de vista antiproductivista tanto si se está a favor como en contra de la centralidad normativa del trabajo, etc. La combinación de estos tres ejes permite una mirada renovada a las maneras como el concep-

10. Véase SAh Lin S (1974) o T h o M PSO n (1967) para corroborar la ausencia de centralidad del trabajo en épocas premodernas.

11. Puede encontrarse esa justificación en N O guera (1998). 
Cuadro 2. Conceptos de trabajo en el pensamiento social.

\begin{tabular}{|c|c|c|c|c|}
\hline & \multicolumn{2}{|c|}{ Concepto reducido } & \multicolumn{2}{|c|}{ Concepto amplio } \\
\hline & Productivista & No productivista & Productivista & No productivista \\
\hline $\begin{array}{l}\text { Asumen la } \\
\text { centralidad } \\
\text { normativa } \\
\text { ded trabajo }\end{array}$ & $\begin{array}{l}\text { A. Smith y } \\
\text { economistas } \\
\text { burgueses } \\
\text { Ética protestante } \\
\text { y «ética del } \\
\text { trabajo» burguesa } \\
\text { K. Kautsky } \\
\text { A. Gramsci } \\
\text { L. Althusser } \\
\text { M arxismo } \\
\text { soviético }\end{array}$ & «Primer» Gorz & $\begin{array}{l}\text { H egel } \\
\text { S. Brzozowski } \\
\text { Ideología de la } \\
\text { «al egría en el } \\
\text { trabajo» (Joy in } \\
\text { work, } \\
\text { Arbeitsfreude) } \\
\text { E. Jünger } \\
\text { N acional- } \\
\text { socialismo }\end{array}$ & $\begin{array}{l}\text { J. Elster } \\
\text { W. M orris } \\
\text { J. Ruskin } \\
\text { Ch. Fourier } \\
\text { T. Carlyle } \\
\text { L. Tolstoi }\end{array}$ \\
\hline $\begin{array}{l}\text { No asumen } \\
\text { la centralidad } \\
\text { normativa } \\
\text { del trabajo }\end{array}$ & F. Engels & $\begin{array}{l}\text { Griegos antiguos } \\
\text { F. Nietzsche } \\
\text { P. Lafargue } \\
\text { G. Lukács } \\
\text { H. Arendt } \\
\text { J. Habermas } \\
\text { «Ú Itimo»Gorz } \\
\text { M arcuse } \\
\text { «maduro» }\end{array}$ & & $\begin{array}{l}\text { K. Marx } \\
\text { T. W. Adorno } \\
\text { M. H orkheimer } \\
\text { «Primer» M arcuse } \\
\text { C. Castoriadis } \\
\text { A. Heller } \\
\text { G. M arkus } \\
\text { Ph. Van Parijs } \\
\text { Feminismo } \\
\text { marxista }\end{array}$ \\
\hline
\end{tabular}

to de trabajo se ha elaborado en la teoría social. Y por lo que se refiere concretamente a las tradiciones marxistas y críticas, estos ejes aportan una luz nueva en otro sentido: a poco que se observe el cuadro, se caerá en la cuenta de que arroja un cierto cambio de perspectiva respecto a las maneras tradicionales de estudiar la tradición marxista, en base a criterios como ortodoxia-heterodoxia, cientificismo-humanismo, o economicismo-culturalismo (así, podemos ver a autores en principio tan distintos como $\mathrm{H}$ abermas y Althusser abogando ambos por un concepto reducido de trabajo, 0 al «heterodoxo» Gramsci junto con los marxistas soviéticos y economistas burgueses en la asunción de un concepto reducido, productivista, y favorable a la centralidad normativa del trabajo).

Una implicación especialmente significativa que se desprende del cuadro 2 es que, contra lo que piensan algunos teóricos como $\mathrm{H}$ abermas o Arendt, es posible mantener una postura favorable a la pérdida de centralidad normativa del trabajo sosteniendo al mismo tiempo el concepto amplio de trabajo. Esto quiere decir que puede ser coherente teóricamente una postura que defienda que ni el trabajo puede o debe ser el vínculo central de la sociedad, ni la racionalidad instrumental tiene por qué ser la única que estructure el trabajo. Esta observa- 
ción resulta importante por cuanto casi todos los pensadores actuales que defienden la tesis de una «crisis de centralidad» del trabajo, o simplemente del empleo (H abermas, O ffe, G orz, M éda...), suelen asumir un concepto reducido de trabajo como algo que se infiere y se deduce de esa posición, con lo que nos abocan a una estrategia basada únicamente en la liberación «del» trabajo, y no tanto «en» el trabajo. Y viceversa, quienes defienden que el trabajo debe seguir siendo al go central en las vidas de los individuos y de cara a la cohesión social, lo suelen hacer muchas veces desde un concepto amplio de trabajo, como actividad necesaria para el reconocimiento social, la autoestima o la autorrealización, cuando no necesariamente ambas cosas van lógicamente ligadas. D igámoslo aún más claro: una estrategia política que busque reducir la centralidad social del trabajo no tiene por qué apoyarse en una imagen puramente instrumental y degradante del mismo.

Como se ha dicho, no vamos a entrar a detallar aquí las posturas de cada uno de los teóricos que aparecen en el cuadro, pero sí haremos algunas observaciones generales sobre algunos de ellos, centrándonos más específicamente en dos pensadores que ejemplifican respectivamente la defensa de un concepto amplio y de uno reducido de trabajo: Karl $\mathrm{M}$ arx y Jürgen $\mathrm{H}$ abermas.

\section{El concepto de trabajo en M arx: crítica de algunos tópicos}

Sostendré a continuación que la obra de $K$ arl $M$ arx constituye una defensa de un concepto amplio de trabajo, esto es, que admite que éste tiene potenciales de autonomía y autorrealización, y no lo reduce a pura actividad instrumental o a una disciplina social o psicológica coercitiva. El concepto de trabajo de $M$ arx es también antiproductivista y no asume la centralidad normativa del trabajo en la sociedad (es decir, aboga por la disolución del vínculo entre trabajo y supervivencia). Resultan, por tanto, incorrectos algunos tópicos que han ido extendiéndose sobre la postura de $\mathrm{M}$ arx respecto del trabajo:

a) En primer lugar, la postura de $M$ arx no constituía en absoluto una glorificación del trabajo, como creen autores como Arendt (1958), Baudrillard (1973), H abermas (1968b y 1985), Jaccard (1960), M éda (1995), N are do (1977 y 1987), o Tilgher (1929): el trabajo es la precondición material de la existencia humana, pero eso es una constatación empírica para M arx, y de ahí no se deriva que el trabajo sea fuente de toda riqueza (ver $M$ arx, 1872: 53 y 1875: 13), de toda moral o de todo progreso. No encontramos nunca en la obra de $M$ arx cantos elegíacos como los de los pensadores liberales o los predicadores protestantes. Tampoco se entiende el trabajo, en M arx, como la esencia del ser humano: éste no es homo faber sino animal social (1872: 397), su socialidad es lo que determina su natural eza y no al revés; es la praxis - entendida como un actuar por el que se va construyendo el mundo- , y no el trabajo - que sería una forma específica de praxis- , lo que define al ser humano y le diferencia de otras especies animales. 
b) En segundo lugar, M arx no adopta una postura productivista, como sí hacía el pensamiento liberal y burgues de su epoca (y contra lo que afirman Anthony, 1977; Baudrillard, 1973; M éda, 1995, o N aredo, 1987). Esindudable que M arx, como la totalidad de pensadores y científicos sociales de su época, no advertía, con la claridad con que hoy lo hacemos, ni la imposibilidad de un desarrollo indefinido de las fuerzas productivas, ni las implicaciones de la destrucción de recursos naturales agotables. Pero también lo es que para M arx la producción económica nunca se planteó como un fin en sí mismo (1857-58, I: 362; 1872: 99, 596, 770-71); por el contrario, la prioridad para él era el desarrollo humano, de tal manera que el ser humano domine y controle la producción, en vez de verse controlado por ella: mediante un afortunado juego de palabras, M arx solía despreciar el goce de la acumulación para oponerlo a la acumulación de goces (1861-63: 283), en un giro casi hedonista. Su actitud claramente favorable hacia la reducción de la jornada laboral y el aumento del tiempo libre documentan también su antiproductivismo (1872: 379 s.). En este sentido, M arx definía la riqueza precisamente como tiempo libre y como autorrealización, no como consumo y acumulación (1857-58, II: 147). Por último, criticaba sin descanso el énfasis del capitalismo en lo puramente mercantil, en el valor de cambio, relegando a un segundo plano el valor de uso de los bienes producidos (1872: 282-283).

c) En tercer lugar, y sobre todo, M arx defiende el concepto amplio detrabajo. Su concepción del trabajo incorpora las tres dimensiones de la acción que se enumeraban más arriba: el trabajo es una actividad orientada a un fin (dimensión cognitivo-instrumental, o teleológica), pero también es interacción social y comunicación (dimensión práctico-moral, o social), así como autoexpresión práctica del ser humano, que desarrolla en él «el libre juego de las fuerzas vitales físicas y espirituales» (1872: 319) (dimensión estético-expresiva). En uno u otro pasaje de su obra, $M$ arx puede hacer mayor o menor énfasis en cada una de estas dimensiones, pero las tres se hallan presentes en el conjunto de sus escritos, desde los M anuscritos hasta la Crítica del programa de Gotha.

La existencia de un concepto amplio de trabajo en la obra de $M$ arx permite además realizar algunas observaciones adicionales: un momento fundamental en dicha obra es la defensa de un concepto de autorrealización activa, que puede darse a través del trabajo, y que no implica la conversión del trabajo en «juego» (como proponían Fourier, Schiller o M arcuse), sino que supone effuerzo e incluso dolor, en cuanto superación de obstáculos para el autodesarrollo de las capacidades y los potenciales humanos ( $M$ arx, 1857-58, II: 119-122; Elster, 1985 y 1989). La autorrealización no consiste para $M$ arx en el mero goce pasivo o el mero consumo, sino que supone actividad y effuerzo, y precisamente por eso puede alcanzarse por medio del trabajo; incluso podría decirse que el trabajo libre y creativo es una de las vías más indicadas - aunque desde luego no la única - para al canzar 
la autorrealización. Esta idea de una autorrealización activa a través del trabajo, que encontramos en M arx, concuerda con estudios psicológicos y sociológicos contemporáneos, que muestran cómo el esfuerzo y la autosuperación son componentes necesarios en la obtención de un sentimiento de autorrealización y plenitud vital (C sikzentmihalyi, 1975 y 1990; Ronco \& Peattie, 1983; Stebbins, 1992).

Contra lo que algunos comentaristas han supuesto, la idea de un trabajo libre no es para M arx una contradicción, sino una posibilidad histórica. Las alusiones de $M$ arx en el Libro III de EI Capital a la diferencia entre el reino de la necesidad y el reino de la libertad (1894: 1043-1044) no deben interpretarse en el sentido de que $M$ arx estuviese oponiendo allí el trabajo al ocio 0 al tiempo libre: si se contextualiza adecuadamente el famoso pasaje - casi siempre abstraído del hilo de la argumentación marxiana - se advierte con claridad que lo que allí se opone es el trabajo necesario (no libre) al plustrabajo libre; el tiempo dedicado a éste último, en la sociedad comunista, se extendería sobremanera según M arx, como consecuencia de la reducción del trabajo necesario posibilitada por la innovación tecnológica; pero, en cualquier caso, el plustrabajo seguiría existiendo, en la forma de actividades libre y conscientemente el egidas por cada individuo para desarrollarse y autorrealizarse como tal.

Si se interpreta la obra de $M$ arx desde estas coordenadas, resulta entonces inevitable concluir que ésta mantiene una clara continuidad en la defensa del concepto amplio de trabajo. D e hecho, la dicotomía alienación-obje tivación (1844b) ya implica la idea de un trabajo libre o desalienado: el trabajo es actividad objetivadora, productora de mundo, pero no por ello debe ser actividad necesariamente alienada. La libertad no está, para M arx, exclusivamente fuera del trabajo, sino, entre otrasinstancias, en el trabajo no alienado. Y esta concepción es también la que separa a M arx, no sólo del concepto reducido de trabajo típico entre los economistas burgueses de su época, sino también de la concepción desvalorizada y elitista que del trabajo tenían los pensadores de la antigüedad (ejemplificada por ejemplo en Aristóteles): para M arx es en la praxis real y material - que incluye el trabajodonde debe darse la buena vida y la liberación, y no sólo en la política, el lenguaje, el pensamiento o el arte, como creía Aristóteles (o como defienden, siglos más tarde, $\mathrm{H}$ abermas 0 Arendt).

d) Por último, cabe añadir a todo lo anterior que $M$ arx no asume la centralidad normativa del trabajo: en textos tan alejados temporalmente como son La ideología alemana y la Crítica del programa de Gotha defiende que la subsistencia no debe estar ligada al rendimiento laboral en la sociedad comunista, sosteniendo así un principio de justicia distributiva igualitarista (y no meritocrático, como el que supuestamente regiría en la sociedad burguesa, según la ideología dominante en la misma): «la diferencia en cuanto a las actividades, a los trabajos, no justifica ninguna desigualdad, ningún privilegio en cuanto a la posesión y al goce» ( $M$ arx y Engels, 1845: 
580). El conocido lema «de cada cual según su capacidad, a cada cual según sus necesidades» evidencia a las claras esta concepción; no en vano teóricos contemporáneos como Philippe Van Parijs (1995) han considerado la propuesta de una renta básica garantizada independiente del trabajo como una vía para hacer realidad aquel principio.

En definitiva, cabe decir que este concepto amplio, no productivista y que no asume la centralidad normativa del trabajo es una de las aportaciones más originales de la obra de M arx.

\section{El concepto de trabajo en las tradiciones marxistas posteriores}

La obra de M arx, debido a su complejidad y dispersión, y a los avatares históricos de su publicación, daba pie para interpretaciones diversas e incluso contradictorias respecto del concepto de trabajo que utilizaba. ¿Podía el trabajo, en su concepción, ser «libre» y «desalienado», o la libertad y la autorrealización humanas estaban por naturaleza más allá de la esfera del trabajo como tal? En la sección anterior se ha intentado argumentar que la primera alternativa es más fiel a la letra y el espíritu de la obra de M arx, y que las interpretaciones en otro sentido encuentran notorias dificultades. Sin embargo, en el pensamiento marxista posterior a $\mathrm{M}$ arx no ha sido infrecuente optar por una u otra de tales posiciones, dando lugar así a lo que podríamos considerar como dos corrientes 0 «tradiciones teóricas» distintas en cuanto a la concepción del trabajo (independientemente de otras divisorias teóricas que a buen seguro podrían clasificar a los autores marxistas o neomarxistas). Así, quienes aceptan la dicotomía «trabajo alienado / trabajo libre» como propia del marxismo estarían implicando un concepto amplio de trabajo (que va más allá de la pura instrumentalidad y hace posible la liberación en el trabajo), mientras que quienes consideran que el trabajo es intrínsecamente alienante de por sí, adoptarían un concepto «reducido» de trabajo, limitándolo a su aspecto instrumental 0 teleológico (y dejando como único objetivo político al respecto la liberación del trabajo).

Esta complejidad en el tratamiento posmarxista del concepto en cuestión (apreciable por ejemplo en el cuadro 2, supra) puede servir para matizar la afirmación de Berki de que el concepto amplio ha sido la tónica dominante en el marxismo: «Los marxistas siempre han creído [...] que el trabajo como la más alta actividad genérica del hombre es, de hecho, una forma de satisfacción» (1979: 54). Esta afirmación requiere, como poco, de una relativización. En muchos autores marxistas el concepto de trabajo reducido se advierte no sólo explícitamente, sino también implícitamente por la completa ausencia de cualquier al usión a temas básicos en M arx, como son los de la autorrealización a tra vés del trabajo, el libre desenvolvimiento del individuo, la alienación, etc. Es cierto que muchos de ellos no conocían aún textos de $\mathrm{M}$ arx como los $\mathrm{M}$ anuscritos o los Grundrisse, pero eso en modo alguno se puede aplicar a todos. Los autores que asumen el concepto reducido, además, pueden dividirse en dos campos: los que además adoptan una visión productivista en alguno de los sentidos que 
se definieron y los que, por el contrario, tienen un punto de vista antiproductivista. En el primer grupo encontramos a Engels, los diversos «marxismos ortodoxos», Gramsci y Althusser; en el segundo, a Lafargue, Lukács, Gorz, el $M$ arcuse «maduro» y $\mathrm{H}$ abermas.

En general, la defensa de un concepto reducido productivista tiene que ver con intereses políticos de disciplinamiento industrial, en aras del desarrollo de las fuerzas productivas como precondición para el socialismo; ello se advierte claramente en Gramsci, cuando en sus fragmentos sobre el «americanismo» y el fordismo aboga claramente por la taylorización y el parcelamiento del trabajo (véase Gramsci, 1932-35), sin detenerse en sus aspectos deshumanizadores, como sí hizo, por ejemplo, en la misma época, Lukács. En cuanto a los autores que defienden el concepto reducido antiproductivista, ello suele tener que ver con una idea de la autorrealización y la libertad mucho más exigente y utópica que la de $\mathrm{M}$ arx, quien como vimos suscribía una idea de autorrealización activa que supone esfuerzo: así, Lafargue (1880), Lukács (1923) 0 $M$ arcuse (1955) se acercan a concepciones filohedonistas y esteticistas que sólo considerarían posible la autorrealización como algo basado en la abolición de la objetividad misma - no únicamente de la alienación - ; mientras que Gorz (1980 y 1988) o H abermas (1983, 1984a y 1984b) toman como inevitable el actual grado de complejidad social que hace sumamente improbable la realización personal en trabajos pautados y mecanizados, deduciendo de ahí que el trabajo debe quedar reducido a su componente puramente instrumental.

0 tros autores situados dentro de la tradición marxista y crítica, sin embargo, han mantenido el concepto amplio y antiproductivista elaborándolo y desarrollándolo más allá de M arx: Adorno (1951: 129; 1966 y 1969) y H orkheimer (1934 y 1947), el M arcuse «joven» (1933), Castoriadis (1975), H eller (1970), M arkus (1986), los marxistas analíticos (Elster, 1989; Van Parijs, 1995) y algunas feministas marxistas, como por ejemplo M aria M ies (1986), han intentado explorar los sentidos y las potencialidades que el concepto amplio de trabajo tenía en $\mathrm{M}$ arx, o simplemente han asumido ese concepto, con diversos grados de implicación. Así, los «padres» de la Escuela de Frankfurt siempre supusieron que en una sociedad racional, no dominada por la lógica de la razón instrumental, el trabajo cambiaría totalmente el sentido alienante y embrutecedor que era su tónica habitual en el capitalismo; se desmarcaron de la «ética del trabajo» burguesa como algo basado en la racionalidad instrumental, y abogaron claramente por la no centralidad del trabajo en la vida. También autores como Cornelius $C$ astoriadis o G yorgy $M$ arkus defendieron un concepto amplio y antiproductivista, con la peculiaridad de que iban incluso más allá de $M$ arx en este empeño, sosteniendo que la obra de éste último pecaba de esencialismo al utilizar conceptos tales como «trabajo necesario» 0 «exigencias técnicas» de la producción; para estos autores no habría separación entre técnica y cultura, sino que la primera - así como las propias «necesidades»- sería siempre una construcción sociohistórica, y por tanto las fronteras de la cosificación podrían retroceder incluso más allá de lo imaginado por 
M arx 0, como mínimo, ser más maleables de lo que él pensaba. O tras corrientes como el marxismo analítico han puesto también énfasis en el concepto amplio al estudiar las posibilidades de autorrealización a través del trabajo (Elster), y han explorado en toda su magnitud la idea de abolir la centralidad social del mismo instaurando una renta básica que disocie la subsistencia de cualquier contraprestación laboral (es el caso de Van Parijs). Por último, feministas marxistas como M ies (1986) han intentado extraer las implicaciones del concepto amplio de trabajo para su aplicación no productivista a los trabajos de las mujeres, y a la lógica específica de los mismos.

\section{La crítica de $\mathrm{H}$ abermas a $\mathrm{M}$ arx y al concepto amplio de trabajo}

El «fin del paradigma de la producción» y el trabajo como acción instrumental

Pero sin duda el desafío teórico más elaborado al que se ha enfrentado el concepto amplio de trabajo de $\mathrm{M}$ arx ha sido el de Jürgen $\mathrm{H}$ abermas. Como es bien sabido, $\mathrm{H}$ abermas acusa a la teoría de $\mathrm{M}$ arx de estar encerrada en el paradigma de la producción y en la filosofía de la conciencia que ha atenazado al pensamiento social moderno. La teoría habermasiana de la acción comunicativa (1981) consistirá básicamente en la sustitución de dicho paradigma, considerado ya caduco, por el paradigma de la comunicación. Podemos esquematizar el argumento de $\mathrm{H}$ abermas como sigue: ${ }^{12}$ el paradigma de la producción parte del modelo de un actor aislado que se enfrenta teleológicamente - es decir, buscando el éxito en la consecución de sus objetivos o finalidades- con un mundo externo «objetivo», ya sea éste social o natural. Es este modelo el que lleva a M arx, según $\mathrm{H}$ abermas, a conceptualizar la categoría de trabajo como la esencial para el proceso de hominización - por el cual la especie huma na se diferencia del resto de especies animales- : el ser humano es, ante todo, homo faber, ser que se enfrenta al mundo y lo transforma instrumentalmente según sus deseos. Pero esta antropología filosófica, afirma $\mathrm{H}$ abermas, es reduccionista: deja de lado otra dimensión esencial para la constitución de la especie humana como tal, cual es la de la interacción social, y más concretamente la de la comunicación y el lenguaje. Tanto uno - trabajo- como otra - comunicación - son esenciales para la autorreproducción del ser humano y de la sociedad (H abermas, 1976: 136 s.). M arx reduciría así toda la praxis social a trabajo social, sin advertir que en las interacciones lingüísticas existen potenciales no reducibles sin más al tipo de actividad teleológica que domina en la esfera del trabajo.

Si el trabajo es para $\mathrm{H}$ abermas el modelo de acción del paradigma de la producción, esto quiere decir que se ve reducido a un carácter puramente teleológico, esto es, a su dimensión cognitivo-instrumental. En la teoría de $H$ abermas, por tanto, el concepto de trabajo sufre la amputación de sus componen-

12. En otro lugar he tratado de exponer con más detalle la crítica de $H$ abermas a los supuestos antropológicos de M arx (N oguera, 1996). 
tes práctico-morales y estético-expresivos. D icho en otros términos, $\mathrm{H}$ abermas opta con claridad y vehemencia por un concepto «reducido» de trabajo. Ya en obras como Ciencia y técnica como «ideología», o Conocimiento e interés (ambas de 1968), y al hilo de su famosa distinción entre trabajo einteracción, H abermas definía «trabajo» como una categoría analítica de acción, que venía a equipararse a la acción instrumental, considerando además que tal identificación estaba implícita en la teoría de M arx. Si la acción instrumental se convierte en modelo categorial, argüía H abermas, la liberación sólo se podía esperar en esa dimensión, esto es, como desarrollo de las fuerzas instrumentales, productivas, del trabajo, y como control técnico del mundo.

¿Se han «agotado los potenciales utópicos del trabajo»?

Pero H abermas, en ensayos posteriores (1983, 1984a, 1984b y 1985) va más allá en su ataque al concepto amplio de trabajo, y lo hace descalificando como trasnochada la concepción «romántica» 0 «expresivista» de autorrealización de la esencia humana a través del trabajo. Para dar cuenta de la liberación de los potenciales humanos, «ya no puede bastar el modelo de la actividad artesanal» (1984a: 407). El concepto de trabajo que se utiliza en sociología y en filosofía está ya (afortunadamente según $\mathrm{H}$ abermas) «purificado de todo contenido normativo» y «jubilado de su papel de fuerza impulsora emancipatoria» (ibídem). La reducción histórica de la jornada laboral y la decreciente importancia del trabajo en la vida hablarían también a favor de esa tesis. Para H abermas, si abandonamos el modelo expresivista, entonces «toda la problemática se reduce a una [... bien modesta medida de política social, a saber: a una humanización del mundo del trabajo» (ibídem: 408). Lo que H abermas quiere decir, en el fondo, es que el trabajo se reduce únicamente a operaciones técnicas, mientras que todo lo que las rebase constituye ya el reino de la comunicación. La alienación, para H abermas, sólo tiene ya sentido combatirla en la comunicación, en aquellas situaciones que impliquen «comunicación sistemáticamente distorsionada», y no en el trabajo como tal. No es la actividad laboral como tal la que puede «desalienarse», sino, en todo caso, su organización comunicativa.

Todo esto es coherente con lo que afirmará también el autor en su Teoría de la acción comunicativa (1981), al hilo de la distinción entre el «sistema» (0 ámbitos regulados por medios de intercambio impersonales y que funcionan independientemente de las orientaciones de acción de los individuos) y el «mundo de la vida» (un mundo práctico y con sentido que no puede funcionar independientemente de las orientaciones de acción de los seres humanos). ${ }^{13}$ En este contexto, el trabajo aparece confinado en el subsistema económico (una parte del sistema, junto con el subsistema político-administrativo). El sis-

13. Puede verse N o guera (1996) o Vallespín (2001) para dos resúmenes de las implicaciones de estos conceptos en la obra de $\mathrm{H}$ abermas. 
tema es el que lleva a cabo la reproducción material del mundo de la vida, y dentro de esa reproducción material está el trabajo social, que incluye, parece ser, únicamente el trabajo pagado (Fraser, 1986).

Para el autor, la moderna automatización del proceso de trabajo y su configuración como una institución «sistémica», el trabajo mecanizado, el taylorismo, etc., habrían privado de sentido a la actividad laboral como algo creativo y autorrealizador, y por ello no hay que buscar ya en ella potencial emancipatorio alguno, sino aceptar lisa y llanamente la exclusividad del aspecto técnico-económico. Y no parece que $\mathrm{H}$ abermas lamente en exceso esa configuración del proceso de trabajo en términos sistémicos, sino que, bien al contrario, considera al mercado de trabajo en cuanto tal, y a la organización «científica» del proceso de trabajo, como un «ogro evolucionario», al desconectar la reproducción material del mundo de la vida de un medio tan precario e incierto como la comunicación.

Para entendernos: según $\mathrm{H}$ abermas, la complejidad y la diferenciación social de las sociedades modernas hacen inevitable la alienación en el proceso de trabajo. La creciente complejidad y diferenciación interna del proceso de trabajo en la sociedad moderna hace ya imposible, según $\mathrm{H}$ abermas, imaginar ningún tipo de «reconciliación» entre el trabajador y su producto, tal y como románticamente esperaba $\mathrm{M}$ arx. Políticamente, esto implica que la vía posible de emancipación no es aumentar los potenciales liberadores del trabajo a expensas de su carácter alienado, de «carga», sino reducir ese «trabajo-carga» al tiempo mínimamente necesario para la reproducción social; esto es, no apostar tanto por un trabajo crecientemente autónomo y autorrealizatorio como por reducir el trabajo a su más pura instrumentalidad. Según sus propias palabras, en el capitalismo tardío «el acento utópico se traslada del concepto de trabajo al de la comunicación» (1984b: 133). Lo único que cabe esperar es, entonces, que los imperativos sistémicos no «colonicen» regiones del mundo de la vida que no les son «propias», pero nada habría que decir si permanecen afincados «en su propio ámbito» de la economía y el estado.

Como afirma el autor en sus Ensayos políticos, todo esto implica «el agotamiento de los potenciales utópicos del trabajo». Sin embargo, observemos ya de entrada que $\mathrm{H}$ abermas está mezclando dos argumentos distintos: una defensa del concepto reducido de trabajo, por un lado, y una crítica de la centralidad normativa del trabajo en la sociedad, por otro. En efecto, a donde quiere llegar $\mathrm{H}$ abermas es a la desvinculación del trabajo respecto del ingreso y la ciudadanía (1984b: 129). Pero para llegar a esta conclusión de crítica de la central idad normativa del trabajo, no es conceptualmente necesario hacer un viaje con tantas alforjas teóricas; en concreto, no es necesaria ni la crítica al concepto amplio de M arx, ni el abandono de «los potenciales utópicos del trabajo» (entendidos como autonomía y autorrealización); nótese, una vez más, que M arx también estaba a favor de queel trabajo se desvinculase respecto a la subsistencia de los individuos (en La ideología alemana o en la Crítica del programa de Gotha), como lo están hoy en día autores como Van Parijs (1995) sin necesidad de adoptar el concepto reducido de trabajo. 


\section{Crítica de la interpretación habermasiana de M arx}

$\mathrm{H}$ ay otras razones que la que se acaba de apuntar para cuestionar la plausibilidad de los argumentos de $\mathrm{H}$ abermas sobre el trabajo. En primer lugar, hay que discutir la interpretación que $\mathrm{H}$ abermas hace del planteamiento de $\mathrm{M}$ arx, y en concreto, la idea de que éste sucumbe a un «reduccionismo categorial». Es una tesis arriesgada la de que $\mathrm{M}$ arx reduzca toda la praxis social a trabajo. Tal y como ponen de manifiesto Kosik (1961) o Sánchez Vázquez (1967), la distinción entre praxis y trabajo es esencial en el marxismo. El trabajo es una forma específica de la praxis, pero, desde luego, no la única. ${ }^{14}$ Tal distinción está claramente implícita en la obra de M arx, y es sólo una comprensión hege lianizante de la misma la que puede llevar a cabo la reducción que preocupa a $\mathrm{H}$ abermas.

C ontra la tesis habermasiana de que lo que hace $M$ arx es «reducir la praxis a trabajo, a la estructura de la acción racional con arreglo a fines» (1985: 274), puede oponerse no sólo el anterior argumento - que la praxis no se reduce a trabajo- , sino también otro ligeramente distinto: que el trabajo no se reduce en $\mathrm{M}$ arx a acción instrumental 0 «racional con arregl 0 a fines». $M$ arx no separa trabajo y comunicación: para él el trabajo humano tiene una dimensión irreductiblemente social (véase su crítica a las «robinsonadas» de los economistas y filósofos burgueses) e incluso comunicativa: baste recordar los famosos pasajes a este respecto en su «extracto sobre James $\mathrm{M}$ ill » (1844a: 290 s.).

N o se pretende negar ni mucho menos que $\mathrm{M}$ arx asume el «paradigma de la producción» en el sentido amplio de «autoexteriorización» de las capacidades humanas. Pero el no haber adoptado el «giro lingüístico» - algo difícil, por no decir imposible, en el contexto intelectual de su época- , para nada es equivalente a haber reducido trabajo 0 acción humana a actividad puramente instrumental. $\mathrm{H}$ abermas Ileva a cabo además una excesiva estetización del concepto de trabajo en el joven M arx. Así, afirma que «El joven M arx asimila [...] el trabajo a la producción creadora del artista, que en sus obras pone fuera de sí sus fuerzas esencial es para volver a apropiarse después el producto en absorta actitud contemplativa» (H abermas, 1985a: 84). Es ésta una visión incompleta: ciertamente hay un componente estético en la idea del trabajo de M arx, pero no es el único. Aquí renace el típico argumento de que $\mathrm{M}$ arx le atribuye una «esencia» inexistente al trabajo humano, y que eso es lo que le permite diferenciar entre trabajo alienado y no alienado, y entre objetivación y alienación. Es cierto que este esencialismo puede darse en M arx, como vimos. Pero sin embargo el modelo de liberación a través del trabajo que $\mathrm{H}$ abermas le atribuye es cuestionable también en otro aspecto: M arx tampoco cree posible vol-

14. SÁn CHEZ VÁzQ UEZ (1967) analiza, en concreto, tres formas de praxis diferenciadas según su objeto: la praxis productiva (trabajo), la artística y la política (que tienen como objetos respectivos la natural eza, los productos de una praxis anterior y lo humano-social). 
ver a la apropiación artesanal del producto, sino a una apropiación a escala social, no individual. ${ }^{15}$

De este modo, el argumento que critica el esencialismo del trabajo como rea lización de una supuesta «natural eza humana auténtica», sin embargo se puede ver acusado a su vez de adoptar el esencialismo de signo opuesto que consiste en asumir que el trabajo es exclusiva y ontológicamente instrumentalidad, y no puede jamás desalienarse.

\section{El esencialismo de la postura de $\mathrm{H}$ abermas}

Son muchos los autores que han criticado los planteamientos de $\mathrm{H}$ abermas como reduccionistas, y que le han reprochado su asimilación esencialista de la categoría de trabajo a la de racionalidad teleológica o instrumental, olvidando otros potenciales de la misma, e incluso realidades históricas bien palpables que expresan tales potenciales. ${ }^{16}$ Algunos de estos autores advierten, entre otras cosas, que el plantamiento de $\mathrm{H}$ abermas resulta ahistórico y esencialista, y que desgaja el trabajo de las relaciones sociales que lo envuelven, asignándole a priori una naturaleza transhistórica.

En epígrafes anteriores vimos que $\mathrm{H}$ abermas reducía el trabajo a acción instrumental por razones puramente teóricas o conceptuales: $\mathrm{H}$ abermas habla a veces de la «racionalidad con arreglo a fines» como «inherente» al «concepto de trabajo» (1985: 87). Pero también hemos visto que, junto al argumento conceptual, $\mathrm{H}$ abermas introduce un argumento histórico-social: no es ya que, conceptual 0 analíticamente, haya que separar «trabajo» de «interacción», o de «acción comunicativa», o de «praxis»; es que el trabajo no puede ser otra cosa que acción instrumental-estratégica debido a su configuración concreta en las sociedades modernas. Como puede verse, existe una cierta tensión en esta dualidad argumental: si la crítica de la categoría de trabajo es necesaria por razones puramente teóricas, y si todo lo que no es instrumental pertenece al ámbito de la praxis, y no del trabajo, entonces no es necesario ningún argumento histórico-social adicional. Por el contrario, si se sostiene el segundo argumento, el histórico-social, cabe cuestionar entonces el primero: si el trabajo sólo ha adquirido su carácter puramente instrumental históricamente, está fuera de lugar el otorgarle ese carácter de forma conceptual, pues históricamente lo puede volver a perder. En suma, la defensa de un concepto «reducido» de trabajo, si sebasa

15. H abermas también afirma que «el modelo expresivista heredado por $M$ arx, que deriva de la transferencia de ciertos ideales estéticos a la esfera del trabajo industrial, encuentra cada vez menos confirmación empírica en la organización de los procesos de trabajo contemporáneos» (1986: 214). Pero M arx nunca esperó ni pretendió hallar confirmación empírica de ese modelo en el proceso de trabajo capitalista alienado, obviamente, luego eso no puede ser un argumento contra él.

16. Baste citar a este respecto a H ONNETH (1982), Gidd ENS (1982), H eller (1976 y 1982), M arkus (1982), Postone (1993), Keane (1975) o Eyerm an y Shipway (1981). 
en un argumento conceptual, hace innecesario y redundante cualquier argumento histórico; y si se basa en un argumento histórico, entra en contradicción con cualquier argumento conceptual. Pero el problema es que el autor parece argumentar en términos conceptuales o histórico-sociales indistintamente según el contexto. Si de entrada entiende «trabajo» como equivalente a «acción instrumental», no cabría entonces hablar de «fin de los potenciales utópicos del tra bajo» causado por razones histórico-sociales, sino de «mposibilidad conceptual» de que el trabajo tenga potencial utópico alguno.

El argumento habermasiano es algo más que un argumento histórico: tiene también un sesgo esencialista. El sistema económico de las sociedades modernas viene a institucionalizar la lógica propia de la actividad laboral, la que de alguna manera le es más «adecuada»: la instrumental-estratégica. Si no fuera porque están pasados de moda, uno casi espera que $\mathrm{H}$ abermas use aquí términos hegelianos y diga que el trabajo ha llegado ya, en las sociedades modernas, a «realizar su propio Concepto». La institucionalización sistémica e instrumental-estratégica del trabajo no es una contingencia histórica cualquiera para H abermas, sino que existe una cierta exigencia interna de la misma: por eso según el autor no es el sistema económico como tal ni el trabajo alienante lo indeseable políticamente, sino sólo la col onización por esa lógica sistémica de otros ámbitos sociales que no son los que «e pertenecen» por derecho propio. En suma: o bien $\mathrm{H}$ abermas está dando un ilegítimo «sal to de nivel» entre lo conceptual y lo histórico-social, o bien está incurriendo en un trasnochado y ahistórico esencialismo.

\section{¿Es el trabajo una realidad inevitablemente «sistémica»?}

Sin embargo, el «esencialismo» de la tesis habermasiana puede atenuarse del siguiente modo: en realidad, $\mathrm{H}$ abermas no afirma que no haya inversión posible de la «sistemicidad» e «instrumentalidad» del trabajo y de la economía, sino que una tal inversión, sin duda históricamente posible, constituiría sin embargo una regresión evolutiva que se pagaría a un precio demasiado alto. No obstante, esta última afirmación nunca queda lo suficientemente justificada por H abermas: ¿cómo sabe que no existen otras posibilidades que la «regresión» social (que habría que discutir también qué quiere decir) o la «sistemicidad» de la economía?, ¿cómo tiene la clarividencia de poder descartar otras evoluciones históricas? ¿N o pueden concebirse cambios en las condiciones de trabajo que empiecen a poner en cuestión el modelo «sistémico» de organización del trabajo, sin por ello regresar a la edad media?

$\mathrm{H}$ ay argumentos más decisivos para no aceptar esta caracterización «sistémica» del trabajo - y de la economía en general- que hace $\mathrm{H}$ abermas. Pues, en efecto, toda una serie de trabajos informales y/o no mercantiles caen fuera de los mecanismos de integración sistémica: aśi ocurre con el trabajo doméstico-familiar de las mujeres, el voluntario o social, los grupos de autoayuda, la autoproducción, el autoconsumo y la autorreparación, el intercambio informal de bienes y servicios, o incluso determinadas profesiones 
artísticas 0 intelectuales. ${ }^{17} \mathrm{~A}$ partir de estos fenómenos puede apreciarse que la inadecuación de la teoría de $\mathrm{H}$ abermas para entender el trabajo es aún más profunda, pues, en efecto, no se trata sólo de que «trabajo» no sea reducible a «sistema»; se trata de que la explicación misma de la diferenciación entre sistema y mundo de la vida se vuelve sumamente débil: la razón de esa diferenciación, según $\mathrm{H}$ abermas, estribaba en que el sistema era un modo «evolucionariamente superior» de asegurar la reproducción material de la sociedad, mientras que la reproducción simbólica se dejaba para el mundo de la vida. Si el sistema no intenta «extender» su lógica más allá de la reproducción material, hacia la simbólica, no se dan patologías sociales. Pero el problema de este planteamiento no es sólo que, como se ha dicho, haya también trabajo en el «mundo de la vida»: es también que todos aquellos trabajos «informales» que se dan en ese «mundo de la vida» aseguran, sin embargo, ciertos aspectos de la reproducción material de la sociedad. La explicación de las «ventajas evolutivas» de la diferenciación del sistema, y de la constitución de la economía en términos sistémicos, cae por su propio peso. $\mathrm{H}$ abermas tiene una visión en extremo teoricista e «idealizada» de la división de la sociedad entre sistema y mundo de la vida. El hecho es que el trabajo, incluido el de reproducción material, puede organizarse y se organiza tanto en términos sistémicos como en términos de «mundo de la vida».

La cuestión es dónde está la frontera entre la «diferenciación» de sistema y mundo de la vida y la «colonización» y «cosificación» del segundo a manos del primero. El trabajo industrial alienado que analizó $M$ arx no sería más que un caso de esta «colonización». Pero M arx, al creer que superando el capitalismo y organizando la producción de otro modo, se desalienaría el trabajo, «subestima la lógica específica de los ámbitos de acción sistémicamente integrados» (1985a: 412). H abría, por tanto, que distinguir entre la parte de alienación que corresponde al capitalismo, y la parte, inevitable, que se debe a la «lógica específica» del sistema, contra la que no se puede luchar, so pena de poner en peligro la integración social «en estenivel de complejidad». Y esa frontera entre las dos «partes» de la alienación es, qué duda cabe para H abermas, una cuestión de hecho, técnica, y no una cuestión práctico-política sobre la que decide la negociación y las luchas sociales. La permanente expresión de $\mathrm{H}$ abermas de que no podemos desdiferenciar el sistema «una vez al canzado un determinado nivel de complejidad», resulta tautológica y resucita los peores defectos de las argumentaciones tel eológicas funcionalistas.

17. Véase, por ejemplo, PAHL, 1984; M IngIOne, 1991; SAnchís, 1988; Ronco y Peattie, 1983; BO RDERíAS y otras, 1994. Para FraSER (1986), el planteamiento de H abermas hace desaparecer el trabajo doméstico-familiar de las mujeres dentro del «mundo dela vida». La diferencia entre sistema y mundo de la vida distrae la atención respecto de que la esfera privada en éste último es también un lugar de trabajo (Fraser, 1986: 60). 
La innecesaria sustitución del paradigma del trabajo por el de la comunicación

Por último, debe decirse que la crítica a $\mathrm{H}$ abermas que aquí se intenta defender no se dirige a regresar al Ilamado «paradigma del trabajo», sino a sostener que éste y el de la comunicación (que defiende $\mathrm{H}$ abermas) pueden ser complementarios y no excluyentes. Por poner un sólo ejemplo, el paradigma de la comunicación parece imprescindible para dar razón de las implicaciones normativas de una teoría social crítica (N oguera, 1996); pero el paradigma del trabajo, si se entiende este concepto de forma amplia y no productivista, puede hacer ver que también en el trabajo existen potenciales emancipatorios para el ser humano, por las posibilidades de autonomía y autorrealización que ofrece. En suma, parecería más fructífero releer la categoría de trabajo desde una teoría de la racionalidad comunicativa, sin que ésta última nos lleve por fuerza hacia un concepto reducido de trabajo. Para ello se podría empezar por mostrar que el trabajo no tiene por qué ser sólo ni principalmente «racionalidad con arreglo a fines».

Ello tiene también implicaciones obvias tanto para la investigación empírica como para la relevancia política a que cualquier teoría crítica aspira. Con el planteamiento de $\mathrm{H}$ abermas, y tal como observa $\mathrm{H}$ onneth, todo potencial o conato de resistencia en el interior del proceso productivo capitalista queda desactivado, y el de trabajo deviene un concepto que «meramente refleja las rela ciones reales de trabajo social [...], perdiendo su significado para la transformación potencial de las formas establecidas del mismo» (H onneth, 1982: 46). El eliminar esa contradicción entre trabajo alienado y no alienado, afirma también $\mathrm{H}$ onneth, priva de su lógica interna a los actos de resistencia dentro de la esfera laboral que son de práctica diaria en el capitalismo tardío, operando como si la liberación de las relaciones de trabajo hubiese llegado ya tan lejos como cabe esperar (ibídem: 54), y como si los problemas del capitalismo ya no tuviesen que ver con la «reproducción material», sino sólo con la «simbólica».

Probablemente hay bastante de cierto en la afirmación habermasiana de que la identificación o reconciliación del trabajador con su producto (en términos tanto individuales como colectivos) es ya, en la mayoría de los casos, un objetivo de dudosa viabilidad si se plantea a escala social; pero no lo es, sin embargo, o lo podría ser cada vez menos, la identificación con la propia actividad laboral como tal, la creciente autorregulación autónoma de la misma, y el control libre por los hombres y mujeres de sus ritmos y cadencias; máxime en aquellas actividades, cada vez más extendidas, donde el producto coincide con la actividad misma (algo que ya advertía M arx en sus Teorías de la plusvalía, cuando analizaba los trabajos de servicios): hay aquí potenciales que un concepto de trabajo como el de H abermas no puede aprovechar. El planteamiento que hace de la alienación laboral como algo irrebasable, es también ciertamente sesgado y selectivo: no advierte, por ejemplo, los diferentes tipos de alienación de que hablaba $M$ arx en sus $M$ anuscritos, de los que $H$ abermas sól o tiene en cuenta la alienación respecto del producto del trabajo, y no las otras 
tres (respecto de la propia actividad, respecto del propio ser genérico del ser humano y respecto de los demás trabajadores); cabe plantear como algo más que una pregunta retórica si esos otros tres tipos de alienación de los que hablaba $\mathrm{M}$ arx pueden ser superados 0 atenuados, en otro tipo de relaciones sociales, sin ningún tipo de «pérdida de complejidad» o de «progreso evolutivo» (e incluso con ganancias en ese aspecto). Alguien tan aficionado a la contrafacticidad como $\mathrm{H}$ abermas podría sin duda calibrar más detenidamente tal posibilidad.

\section{Algunas posibles implicaciones: ttiene sentido aún el concepto de trabajo?}

Se ha intentado sostener que resulta viable y teóricamente coherente la defensa de un concepto amplio de trabajo; el trabajo, lejos de reducirse a una lógica puramente instrumental o sistémica, puede ser una vía entre otras para la generación de solidaridad social y para el logro de la autorrealización de los individuos. Algunas de las posibles implicaciones del planteamiento expuesto se enumeran, sin ánimo de exhaustividad, a continuación.

En primer lugar, la defensa de un concepto amplio y antiproductivista de trabajo, entendido en las tres dimensiones que se han especificado, puede ser una ayuda teórica para mantener aún hoy el concepto unificado y abstracto de «trabajo» nacido en el siglo XVIII como categoría coherente de actividad (aunque pueda cobrar contenidos diferentes); y ello contra los ataques sociologistas o relativistas a esa categoría, que buscan disolverla (Baudrillard, 1973; Foucault, 1966; N aredo, 1997), como también contra una posición esencialista o nominalista que la abstraiga de su evolución histórica y de su carga política, cayendo en el reduccionismo de identificar trabajo y empleo asalariado ( $\mathrm{H}$ abermas, 1984b; M éda, 1995). El concepto en tres dimensiones que aquí se propone puede dotar de cierto sentido al mantenimiento de una categoría unificada de «trabajo». Así, desde la dimensión cognitivo-instrumental, el trabajo puede concebirse como actividad orientada a la producción o creación de valores de uso. Pero es cierto que esta dimensión no da sentido a dicha actividad: es necesaria la dimensión práctico-moral, que está contenida en el carácter social del trabajo; el trabajo es socialidad en sí misma tanto como instrumentalidad, y por ello puede generar sentido. Y no cabe olvidar tampoco la dimensión estético-expresiva del trabajo (sin duda la más frustrada en nuestra sociedad), como medio de creación y autorrealización personal. D escartar la posibilidad de que estas dos últimas dimensiones cobren mayor protagonismo en el futuro del trabajo humano supondría caer en posturas esencialistas.

En segundo lugar, a partir de estas premisas cabe evidenciar cómo las hoy muy comentadas tesis sobre la pérdida de centralidad del trabajo pueden también ser defendidas desde un concepto amplio de trabajo, y no desde uno reducido. D e hecho, el concepto amplio de trabajo - el que considera posible la autonomía y la autorrealización en el mismo- no implica necesariamente ideas como las de que el trabajo deba ser la única vía de autorrealización vital, ni siquiera la central; tampoco permite deducir automáticamente que el tra- 
bajo deba ser la instancia estructuradora por excelencia de la vida social, o que deba asociarse en exclusiva a todo tipo de beneficios y recursos sociales y culturales. La reivindicación de una renta básica garantizada independiente del trabajo, por ejemplo, a menudo se basa precisamente en el concepto amplio, al suponer que los individuos no trabajan únicamente por motivos instrumentales - como la obtención de ingresos- , y por lo tanto continuarían desa rrollando actividades socialmente útiles y económicamente valiosas aun cuando su subsistencia material no dependiese de ello; los estímulos e incentivos para el desarrollo de tales actividades no estarían ya basados en la coerción económica y/o política, sino en los vínculos de solidaridad social y las necesidades personales de autodesarrollo de capacidades y potencialidades.

En tercer lugar, el planteamiento aquí defendido puede ayudar a la crítica ideológica de algunos discursos sobre el «fin del trabajo» o el «futuro del trabajo en la sociedad posindustrial», que únicamente hacen énfasis en los aspectos tecnológicos o cognitivo-instrumentales, sin reparar en que el trabajo no se reduce al empleo formal asalariado, y en que el «fin del trabajo» como tal supondría nada menos que el fin de la humanidad.

En cuarto lugar, desde el punto de vista de la investigación empírica, el esquema expuesto puede contribuir a una mayor comprensión de los cambios en las orientaciones hacia el trabajo (Zoll, 1992): diferencia mejor los aspectos cognitivo-instrumentales de los estético-expresivos presentes en tales orientaciones; puede ayudar a distinguir con mayor precisión - tanto histórica como sociológicamente - la «ética del trabajo» propia del «viejo modelo cultural», respecto de las nuevas orientaciones posproductivistas, que estarían más basadas en lo que hemos Ilamado un "concepto amplio de trabajo»; puede dar, asimismo, elementos para comprender algunas contradicciones o ambigüedades aparentes en los discursos de los actores sociales sobre su relación con el trabajo (como, por ejemplo, que los mismos individuos suel an combinar actitudes instrumentales y expresivas hacia el trabajo); etc.

Por último, el planteamiento que aquí se defiende viene inspirado también por determinadas motivaciones políticas, que buscarían ayudar a aumentar la discusión pública en torno a temas como los de la humanización del trabajo o los cambios en la natural eza del trabajo o en su organización, de forma que se maximizasen los potenciales de autonomía y autorrealización que pueden existir en él. Sería una ironía histórica el que, precisamente en la civilización más rica y tecnológicamente avanzada que se ha conocido, los hombres y las mujeres asumiesen como algo inevitable e insuperable la alienación y el empobrecimiento vital en una actividad tan cotidiana como es el trabajo. Las propuestas posmarxistas actuales de instaurar una renta básica incondicional o un socialismo de mercado con democracia económica, bien podrían convertirse en puntales básicos de las luchas sociales en el siglo que acaba de nacer. 


\section{Bibliografía}

Ad o Rn O, Theodor W. (1951). M inima moralia. M adrid: Taurus, 1987.

- (1966). Dialéctica negativa. M adrid: Taurus, 1975.

- (1969). «Tiempo libre». En Consignas. Buenos Aires: Amorrortu, 1973.

A Lon So, Luis Enrique (1999). Trabajo y ciudadanía. Estudios sobre la crisis de la socie dad salarial. M adrid: Trotta.

- (2000). Trabajo y postmodernidad: el empleo débil. M adrid: Fundamentos.

AN D ERSO N, Perry (1976). Consideraciones sobre el marxismo occidental. M adrid: Siglo XXI, 1979.

- (1983). Tras las huellas del materialismo histórico. M adrid: Siglo XXI, 1986.

ANTH ONY, Peter D. (1977). Thel deology of Work. Londres: Tavistock.

ApPLEBAu M , H erbert (1992). The Concept of Work. Albany: SU N Y Press.

AREN DT, H annah (1958). La condición humana. Barcelona: Paidós, 1993.

BATTAGLIA, Felice (1951). Filosofía del trabajo. M adrid: Editorial Revista de D erecho Privado, 1955.

- (1973). «W ork». En W IEN ER, Phillip P. (ed.). D ictionary of the H istory of I deas, (vol. IV). N ueva York: Charles Scribner's Sons.

BAUD RILLARD, Jean (1973). El espejo de la producción. Barcelona: G edisa, 1996.

BAUM AN, Zygmunt (1998). Trabajo, consumi smo y nuevos pobres. Barcelona: Gedisa, 2000.

BERKI, R. N . (1979). «O $n$ the N ature and O rigins of M arx's C oncept of Labor». Political Theory, vol. 7, no 1.

Borderías, C ristina; Carrasco, Cristina; Alem any, Carmen (comp.) (1994). Las mujeres y el trabajo. Rupturas conceptuales. Barcelona: Icaria-FU H EM .

CASTO RIAD IS, Cornelius (1975). The Imaginary Institution of Society. C ambridge: Polity Press, 1987.

C SIKZENTM M IH ALYI, M ihaly (1975). Beyond Boredom and Anxiety. The Experience of Play in Work and Games. San Francisco: Jossey-Bass Publishers.

- (1990). Flow. The Psychology of O ptimal Experience. NuevaYork: H arper-Collins Publishers.

De GrazIA, Sebastian (1962). Of Time, Work and Leisure N ueva York: Anchor Books, 1964.

DíEZ, Fernando (2001). U tilidad, deseo y virtud. La formación dela idea moderna de trabajo. Barcelona: Península.

ELSTER, Jon (1985). M aking Sense of M arx. Cambridge: C ambridge U niversity Press.

- (1989). «Self-realisation in work and politics: the M arxist conception of the good life». En ELSTER, Jon; M Oene, Karl O . (eds.). Alternatives to Capitalism. Cambridge: Cambridge University Press.

EYERM AN, R.; SHIPWAY, D. (1981). «H abermas on Work and Culture». Theory and Society, vol. 10, № 4.

Fou CAULT, M ichel (1966). Laspalabrasy las cosas. Una arqueología delas cienciashumanas. M éxico: Siglo XXI, 1974.

Fraser, $N$ ancy (1986). «¿Q ué tiene de crítica la teoría crítica? H abermas y la cuestión del género», en Seyla BeN H ABIB y D rucilla Co RN ELL (eds.). Teoría feminista y teoría crítica. Valencia: Ed. Alfons el M agnànim, 1990.

GIDDEN S, Anthony (1982). «Trabajo e interacción en H abermas». En Política, sociología y teoría social. Barcelona: Paidós, 1997.

Go Rz, André (1980). Farewell to the Working Class. An Essay on Post-industrial Socialism. Boston: South End Press, 1982. 
- (1988). M etamorfosis del trabajo. M adrid: Sistema, 1995.

- (1997). M isères du présent. Richesse du possible. París: G alilée.

G RAM SCI, Antonio (1932-1935). «Racionalización de la producción y del trabajo» y «Taylorismo y mecanización del trabajador». En Antología (comp. de M. Sacristán). M éxico: Siglo XXI, 1978.

H ABERM AS, Jürgen (1968a). Ciencia y técnica como «ideología». M adrid: Tecnos, 1984.

- (1968b). C oneixement i interès. Barcelona: Edicions 62, 1987.

- (1976). La reconstrucción del materialismo histórico. M adrid: Taurus, 1981.

- (1981). Teoría de la acción comunicativa (2 vols.). M adrid: Taurus, 1987.

- (1983). «Política conservadora, trabajo, socialismo y utopía hoy». En Ensayos políticos. Barcelona: Península, 1988.

- (1984a). «Respuesta a mis críticos». En Teoría de la acción comunicativa: Comple mentos y estudios previos. M adrid: Cátedra, 1989.

- (1984b). «La crisis del Estado de bienestar y el agotamiento de las energías utópicas». En Ensayos políticos. Barcelona: Península, 1988.

- (1985). El discurso filosófico de la modernidad. M adrid: Taurus, 1989.

- (1986). Autonomy and Solidarity. Interviews with J. H abermas, Londres: Verso.

H eller, Agnes (1970). Sociología de la vida cotidiana. Barcelona: Península, 1977.

- (1981). «Paradigm of production: paradigm of work». D ialectical Anthropology, no 6 .

- (1982). «H abermas and M arxism». En D. H eld y J. B. Th OM PSON (eds.): H abermas: Critical D ebates. Londres: M acM illan.

- (1982). «W ork and Instrumental Action». N ew German Critique, no 26.

H ONNETH, Axel (1993). «T he social dynamics of disrespect: situating C ritical The ory today». En D Ews, Peter (ed.). H abermas: A Critical Reader. O xford: Blackwell, 1999.

H O RKHEIM ER, M ax (1934). H ora foscant. Barcelona: Edicions 62, 1984.

- (1947). Crítica de la razón instrumental. Buenos Aires: Sur, 1973.

JACCARD, Pierre (1960). H istoria social del trabajo. D ela antigüedad hasta nuetros días. Barcel ona: Plaza y Janés, 1971.

J AY, M artin (1984). M arxism and Totality. The Adventures of a Concept from Lukács to $\mathrm{H}$ abermas. Cambridge: Polity Press.

KEAN E, John (1975). «O n Tools and Language: H abermas on Work and Interaction». N ew German Critique, $\mathrm{n}$ o 6.

Ko sIK, K arel (1961). D ialèctica del concret. Barcelona: Edicions 62, 1970.

KWAN T, Remy C. (1960). Philosophy of Labor. Lowain: Editions E. N auwelaerts.

Lafargue, Paul (1880). El derecho a la pereza. M adrid: Fundamentos, 1991.

LUKÁCS, Georg (1923). H istoria y consciencia de dase (2 vols.). Barcelona: O rbis, 1985. M ARCU SE, H erbert (1933). «Sobre els fonaments filosòfics del concepte econòmico-científic del treball». En Filosofia i política. Barcelona: Edicions 62, 1971.

- (1955). Erosy civilización. Barcelona: Ariel, 1984.

M ARKUS, G yorgy (1982). L anguage and Production. A Critique of the Paradigms. D ordrecht: D. Reidel Publishing Company, 1986.

- (1986). «Praxis and Poiesis: Beyond the D ichotomy». Thesis Eleven, no 15.

M ARX, Karl (1844a). «Extractos de lectura: James M ill». En M anuscritos de París. Anales Francoalemanes (OM E, vol. 5). Barcelona: Grijalbo, 1978.

- (1844b). M anuscritos: economía y filosofía. M adrid: Alianza, 1985.

- (1857-1858). Elementos fundamentales para la crítica de la economía política (Grundrisse) (3 vol.). M adrid: Siglo XXI, 1976. 
- (1861-1863). Teorías sobre la plusvalía (O M E, vol. 45). Barcelona: Grijalbo, 1977.

- (1868). «C arta a Kugelmann». En M ARX, Karl; En GELS, Friedrich. Cartas sobreEI Capital. Barcelona: Laia, 1974.

- (1872). El Capital. Crítica de la economía política. Libro I: El proceso de producción del capital (3 vol.). M éxico: Siglo XXI, 1990 (vol. 1) y 1988 (vols. 2 y 3).

- (1875). «C rítica del programa de G otha». En M ARX, Karl; EN GELS, Friedrich. Crítica del s programes de G otha i Erfurt. Barcelona: Edicions 62, 1971.

- (1894). El Capital. Crítica de la economía política. Libro III: El proceso gl obal de la producción capitalista (3 vol.). M adrid: Siglo XXI, 1976-1981.

M ARX, Karl; EN GELS, Friedrich (1845). La ideología alemana. Barcelona: L'Eina editorial.

M ÉDA, D ominique (1995). El trabajo. Un valor en peligro de extinción. Barcelona: Gedisa, 1998.

M IES, M aria (1986). Patriarchy and Accumulation on a World Scale. Londres: Zed Books.

M IN GIONE, Enzo (1991). Las sociedades fragmentadas. M adrid: M inisterio de Trabajo y Seguridad Social, 1993.

N ARED O, José M anuel (1977). «El trabajo es un castigo». Cuadernos para el diálogo, 26 de marzo.

- (1987). La economía en evolución. H istoria y perspectivas de las categorías básicas del pensamiento económico. M adrid: Siglo XXI-M inisterio de Economía y $\mathrm{H}$ acienda.

- (1997). «C onfiguración y crisis del mito del trabajo». En VV. AA. ¿Q ué crisss?: Retos y tran formaciones de la sociedad del trabajo. D onostia: H irugarren Prentsa S. L.

N EGRI, Antimo (1980-1981). Filosofia del lavoro. Storia antologica (7 vols.). M ilán: $M$ arzorati Editore.

N o guera, José Antonio (1996). «La teoría crítica: de Frankfurt a H abermas». Papers, n 50.

- (1997). «La fi de la societat del treball?». N ous H oritzons, № 148 (invierno).

- (1998). La transformación del concepto de trabajo en la teoría social. La aportación de las tradiciones marxistas. Tesis doctoral. Barcelona: Universidad Autónoma de Barcelona.

- (2000). «El problema de la definición del trabajo». Ponencia presentada en los I Encuentros entre H umanidades y Ciencias Sociales (Institut U niversitari de C ultura, Universitat Pompeu Fabra, 18-20 de enero de 2000).

PAHL, R. E. (1984). D ivisiones del trabajo. M adrid: M inisterio de Economía y Seguridad Social, 1991.

Pieper, Josef (1952). Leisure. The Basis of Culture. Scarborough (O ntario): The N ew American Library, 1963.

Postone, M oishe (1993). Time, Labor and Social D omination. C ambridge: Cambridge University Press.

Rod GERS, D aniel T. (1978). The Work Ethic in Industrial America, 1850-1920. Chicago: U niversity of C hicago Press, 1979.

Ron co, W illiam; PeAT TIE, Lisa (1983). M aking Work: self-created jobs in participatory organizations. N ueva York: Plenum Press.

SAH LIN S, M arshall (1974). La economía de la Edad de Piedra. Madrid: Akal, 1977.

SÁn CHEZ VÁzQ UEZ, Adolfo (1967). Filosofía de la praxis. M éxico: Grijalbo.

SAN CH Ís, Enric; M IÑ AN A, José (eds.) (1988). La otra economía: trabajo negro y sector informal. Valencia: Alfons el M agnànim.

Sen netT, Richard (1998). La corrosión del carácter. Las consecuencias sociales del trabajo en el nuevo capitalismo. Barcelona: Anagrama, 2000. 
Stebiln S, Robert A. (1992). Amateurs, Professionals and Seri ous Leisure. M ontreal: M cG ill-Q ueen's U niversity Press.

Th OM PSO N, Edward P. (1967). «Tiempo, disciplina de trabajo y capitalismo industrial». En Tradición, revuelta y consciencia de clase. Barcelona: Crítica, 1979.

TILGH ER, Adriano (1929). Work: What It H as M eant to M en Through the Ages (H omo Faber). N ueva York: H arcourt, Brace and Company, 1930.

V ALLESPín, Fernando (2001). «H abermas en doce mil palabras». Claves de razón práctica, no 114 (julio-agosto).

Van PARIJs, Philippe (1995). Libertad real para todos. Qué puedejustificar al capitali smo (si hay algo que pueda hacerlo). Barcelona: Paidós, 1996.

W eber, M ax (1904-1905). La ética protestantey el espíritu del capitalismo. Barcelona: O rbis, 1985.

ZoLL, Rainer (1992). N ouvel individualisme et solidarité quotidienne. París: Kimé. 